\title{
Electrogenic Sodium/Bicarbonate Cotransport in Rabbit Renal Cortical Basolateral Membrane Vesicles
}

\author{
Takashi Akiba, Robert J. Alpern, ${ }^{\star}$ Jill Eveloff,ł Justina Calamina, and David G. Warnock \\ Nephrology Section, Veterans Administration Medical Center, San Francisco, California 94121, and Cardiovascular Research Institute \\ and Department of *Medicine and $¥$ Physiology, University of California, San Francisco, California 94143
}

\begin{abstract}
The present studies examined the mechanism of bicarbonate transport across basolateral membrane vesicles prepared from rabbit renal cortex. Isotopic sodium uptake was stimulated by bicarbonate when compared with gluconate $(2.5 \mathrm{nmol} / \mathrm{mg}$ protein per $5 \mathrm{~s}$ versus $1.4 \mathrm{nmol} / \mathrm{mg}$ protein per $5 \mathrm{~s}$ ), and this process was inhibited by disulfonic stilbenes. Imposition of an interiorpositive potassium diffusion potential further stimulated isotopic sodium uptake to $3.4 \mathrm{nmol} / \mathrm{mg}$ protein per $5 \mathrm{~s}$, an effect that occurred only in the presence of bicarbonate and was blocked by disulfonic stilbenes. Kinetic analysis of the rate of bicarbonatedependent sodium uptake as a function of sodium concentration revealed saturable stimulation with a $V_{\max }$ of $2.7 \mathrm{nmol} / \mathrm{mg}$ protein per $2 \mathrm{~s}$ and a $K_{\mathrm{m}}$ of $10.4 \mathrm{mM}$. The effect of bicarbonate concentration on bicarbonate-dependent sodium uptake was more complex. The present results demonstrate an electrogenic (negatively charged) sodium/bicarbonate cotransporter in basolateral membrane vesicles from the rabbit renal cortex. The electrogenicity implies a stoichiometry of at least two bicarbonate ions for each sodium ion.
\end{abstract}

\section{Introduction}

The mammalian proximal convoluted tubule reabsorbs most of the filtered load of bicarbonate by proton secretion into the lumen (1). This process requires in the steady state that an equal number of base equivalents be transported out of the cell across the basolateral membrane (1). The mechanisms of bicarbonate exit across the basolateral membrane have not been fully described. Electrophysiological observations of the response to changes in peritubular bicarbonate concentration have demonstrated a conductive mechanism for bicarbonate transport in rat $(2,3)$, amphibian $(4,5)$, and rabbit proximal tubule $(6)$.

Boron and Boulpaep (5) used $\mathrm{pH}-, \mathrm{Na}^{+}$-, and $\mathrm{Cl}^{-}$-sensitive microelectrodes to study basolateral bicarbonate transport in isolated perfused proximal tubules of the tiger salamander. They concluded that bicarbonate flux is linked with sodium flux in a manner consistent with electrogenic sodium/bicarbonate cotransport, because sodium, bicarbonate, and net negative charge are carried in the same direction. Other workers have demon-

Portions of these results have been reported in abstract form (Kidney Int. 1986. 29:362. (Abstr.)

Address correspondence and reprint requests to D. G. Warnock, M.D., Department of Medicine (111J), Veterans Administration Medical Center, 4150 Clement St., San Francisco, CA 94121.

Received for publication 21 January 1986 and in revised form 19 June 1986.

The Journal of Clinical Investigation, Inc.

Volume 78, December 1986, 1472-1478 strated an electrogenic sodium/bicarbonate cotransport system with electrophysiologic techniques in rat and rabbit proximal tubules $(7,8)$. Sodium/bicarbonate cotransport has also been demonstrated in the basolateral membrane by fluorometric measurements of intracellular $\mathrm{pH}$ in microperfused rat proximal convoluted tubules in vivo $(9,10)$. Recent studies have also identified this system in cultured kidney epithelial cells of monkeys (11).

The purposes of the present studies were to confirm the presence of a sodium/bicarbonate cotransporter and to characterize this system in basolateral membrane vesicles prepared from the rabbit renal cortex. We herein describe the effect of bicarbonate on sodium transport in basolateral membrane vesicles under clearly defined experimental conditions. Our findings imply that the bicarbonate/sodium stoichiometric ratio of this transport system is greater than unity, which would be consistent with an electrogenic sodium/bicarbonate cotransport system.

\section{Methods}

Materials. All chemicals and enzymes were obtained from Sigma Chemical Co., St. Louis, MO, unless noted, and were of the highest purity available. $1 \mathrm{M} \mathrm{N}$-methyl glucamine gluconate ( $\mathrm{pH} 7.5$ ) was made by the titration of $1 \mathrm{M} N$-methyl glucamine with $d$-gluconic acid lactone. SITS 1 (4-acetamido-4'-isothiocyanostilbene-2',2-disulfonic acid) and DIDS (4,4'diisothiocyanostilbene-2',2-disulfonic acid) were obtained from Pierce Chemical Co., Rockford, IL. ${ }^{22} \mathrm{Na}$ was purchased from New England Nuclear, Boston, MA.

Membrane preparation. Basolateral membrane vesicles from rabbit kidney cortex were prepared by differential and sucrose gradient centrifugation, as described by Ives et al. (12). In brief, both kidneys of female New Zealand white rabbits weighing $1.0-1.5 \mathrm{~kg}$ were perfused via the renal artery with $35 \mathrm{ml}$ of ice-chilled buffer ( $10 \mathrm{mM}$ Hepes/Tris, pH 7.5, $250 \mathrm{mM}$ sucrose, $5.0 \mathrm{mM}$ EGTA). The cortex of each kidney was sliced and homogenized with an Omni mixer (Dupont Instruments, Newton, CT; setting 10; $4 \mathrm{~min}$ ) in the same buffer. The resultant slurry was centrifuged for $15 \mathrm{~min}$ at $2,450 \mathrm{~g}$. Supernatants were recentrifuged at $35,000 \mathrm{~g}$ for $30 \mathrm{~min}$. The fluffy layer of the pellet was suspended in $250 \mathrm{mM}$ sucrose, $10 \mathrm{mM}$ Hepes/Tris, $\mathrm{pH} 7.5,1 \mathrm{mM}$ magnesium chloride buffer, homogenized by passing through a 22 -gauge needle and recentrifuged at $50,000 \mathrm{~g}$ for $30 \mathrm{~min}$. The resulting fluffy layer was resuspended

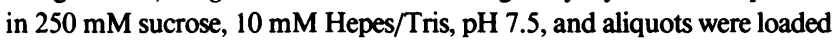
on linear $25-45 \%$ (wt/vol) sucrose density gradients containing $10 \mathrm{mM}$ Hepes/Tris, pH 7.5, and centrifuged at $100,000 \mathrm{~g}$ for $16 \mathrm{~h}$. Twelve fractions were obtained, and maltase (13) and $\mathrm{Na}, \mathrm{K}$-dependent ATPase (14) activities were determined. Peak fractions of $\mathrm{Na}, \mathrm{K}$-dependent ATPase activity were pooled and used as the basolateral membrane vesicles. The enrichments of $\mathrm{Na}, \mathrm{K}$-dependent ATPase activity and maltase activity of the basolateral membrane vesicle preparation compared with the homogenates were $16.44 \pm 0.06$ and $1.51 \pm 0.10$-fold (mean $\pm \mathrm{SE}, n=6$ ), respectively. The sideness of the vesicles was estimated from the latency

1. Abbreviations used in this paper: DIDS, 4,4'-diisothiocyanostilbene2',2-disulfonic acid; SITS, 4-acetamido-4'-isothiocyanostilbene-2,2'-disulfonic acid. 
of $\mathrm{Na}, \mathrm{K}$-dependent ATPase by disruption with $1 \mathrm{mg} / \mathrm{ml}$ deoxycholate and equilibration with monensin $(15,16)$. Unassignable vesicles, namely sheets or leaky vesicles, accounted for $43.5 \pm 4.1 \%$ (mean $\pm S E$ ) of the total $\mathrm{Na}, \mathrm{K}$-dependent ATPase activity in nine separate preparations. The results of the estimation of vesicle orientation were right-side-out vesicles, $98.3 \pm 0.7 \%$, and inside-out vesicles $1.6 \pm 0.7 \%$ of the assignable membranes. Bicarbonate-dependent ${ }^{22} \mathrm{Na}$ uptake activity was found in fractions with $\mathrm{Na}, \mathrm{K}$-dependent ATPase activity, and was not observed in the maltase-rich fractions (data not shown). Protein was assayed by the method of Lowry et al. (17).

Transport measurements. Uptake of ${ }^{22} \mathrm{Na}$ was measured at $25^{\circ} \mathrm{C}$ by a rapid filtration technique. The membrane vesicles were preincubated for $2 \mathrm{~h}$ in a medium of $200 \mathrm{mM}$ sucrose, $50 \mathrm{mM}$ Hepes/Tris, pH 7.5, and $1 \mathrm{mM}$ magnesium gluconate at room temperature. The experiment was initiated by addition of $20 \mu \mathrm{l}$ membrane suspension to $110 \mu \mathrm{l}$ of uptake media. The final concentrations are given in figure legends. The uptake period was terminated by rapid mixture of $20 \mu \mathrm{l}$ of incubation mixture with $1.5 \mathrm{ml}$ of ice-cold stop solution containing $200 \mathrm{mM}$ sucrose, $50 \mathrm{mM}$ Hepes/Tris, $\mathrm{pH} 7.5$, and $40 \mathrm{mM}$ potassium sulfate. Uptake periods of $<5 \mathrm{~s}$ were timed with a metronome as described by Wright et al. (18). In these studies, $5 \mu \mathrm{l}$ of membrane suspension were rapidly mixed by vortexing with $25 \mu \mathrm{l}$ incubation buffer, and the reactions were terminated by rapid injection of $1.5 \mathrm{ml}$ of ice-cold stop solution. This mixture was rapidly transferred to a prewetted $0.45-\mu \mathrm{m}$ filter (Millipore/ Continental Water Systems, Bedford, MA) and washed with an addition of $3 \mathrm{ml}$ stop solution. Filters were placed into scintillation vials and counted by scintillation spectroscopy. Fig. 1 shows that the rapid uptake method provided accurate measurements of the initial rate of bicarbonatedependent (left) and bicarbonate-independent (right) ${ }^{22} \mathrm{Na}$ uptake for intervals up to $3 \mathrm{~s}$. Results are expressed as mean $\pm \mathrm{SE}$, and $n$ refers to the number of experiments, each of which was done with separate membrane preparations.

Uptake media. Uptake media containing different concentrations of bicarbonate were made by mixing 1 vol of potassium bicarbonate stock solutions with 4 vol of a buffer containing $62.5 \mathrm{mM}$ Hepes/KOH, pH 7.5 , and appropriate concentrations of sodium gluconate and potassium gluconate. The $\mathrm{pH}$ stability of this medium was examined in a preliminary experiment (Fig. 2). The change from the initial $\mathrm{pH}$ increased with time after mixing but was $<0.12 \mathrm{pH} \mathrm{U}$ during the initial $15 \mathrm{~min}$. The change

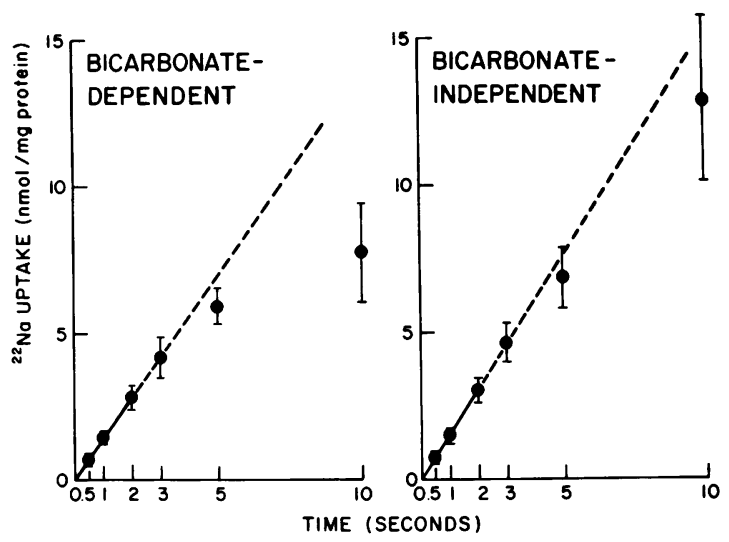

Figure 1. The time course of ${ }^{22} \mathrm{Na}$ uptake in renal basolateral membrane vesicles. Vesicles were preincubated in a buffer containing 200 $\mathrm{mM}$ sucrose, $50 \mathrm{mM}$ Hepes/Tris, $\mathrm{pH} 7.5,1 \mathrm{mM}$ magnesium gluconate, and $7 \mu \mathrm{M}$ valinomycin. The transport medium contained $1 \mu \mathrm{Ci}$ ${ }^{22} \mathrm{Na}$, and when mixed with the vesicle suspension, resulted in final concentrations of $42 \mathrm{mM}$ sodium, $42 \mathrm{mM}$ bicarbonate or $42 \mathrm{mM}$ gluconate, $65 \mathrm{mM}$ potassium gluconate, and $50 \mathrm{mM}$ Hepes/KOH buffer, $\mathrm{pH}$ 7.5. The rate of ${ }^{22} \mathrm{Na}$ uptake in the presence of gluconate (bicarbonate-independent, right) was subtracted from the total uptake rate to gave the rate of bicarbonate-dependent ${ }^{22} \mathrm{Na}$ uptake (left). Each point and bar represents the mean and SE of three uptake experiments with different vesicle preparations.

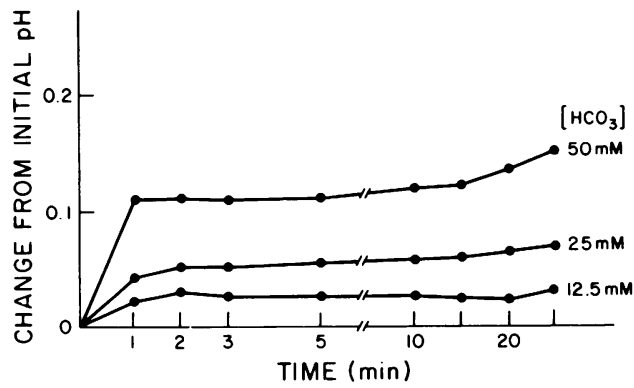

Figure 2. Effect of bicarbonate addition on the $\mathrm{pH}$ of ${ }^{22} \mathrm{Na}$ uptake media. 4 vol of a buffer containing $62.5 \mathrm{mM}$ Hepes/Tris, pH 7.5, 12.5 $\mathrm{mM}$ sodium gluconate and $112.5 \mathrm{mM}$ potassium gluconate were mixed with 1 vol of potassium bicarbonate with a final bicarbonate concentration given on the figure. The $\mathrm{pH}$ of the mixed media was measured continuously for $25 \mathrm{~min}$ with a glass electrode $\mathrm{pH}$ meter and gentle stirring.

in bicarbonate concentration was $< \pm 2 \%$ of the prescribed value. All uptake studies were done within $10 \mathrm{~min}$ of mixing of each potassium bicarbonate stock solution with Hepes/Tris buffer.

\section{Results}

The experimental strategy for investigating sodium/bicarbonate cotransport is indicated in Fig. $3 .{ }^{22} \mathrm{Na}$ uptake rates were measured with an uptake media containing either bicarbonate or gluconate (Fig. 3, top). If there is a sodium/bicarbonate cotransport system, increased ${ }^{22} \mathrm{Na}$ uptake will be observed in the presence of bicarbonate compared with gluconate. Furthermore, previous studies (5-11) have shown that SITS can inhibit sodium/bicarbonate cotransport. The effect of inwardly directed potassium diffusion potentials on sodium/bicarbonate cotransport were also examined (Fig. 3, bottom). The potential was established by a high potassium concentration in the external medium, and the potassium ionophore, valinomycin. Simple sodium diffusion should be inhibited by the interior-positive potential. In contrast, this positive potential should stimulate electrogenic sodium/bicarbonate cotransport if the bicarbonate/ sodium stoichiometric ratio is greater than unity. Once again, SITS should inhibit the sodium/bicarbonate cotransporter.

In the first series of experiments, we demonstrated the presence of an electrogenic sodium/bicarbonate cotransporter in the basolateral membrane vesicles. Fig. 4 summarizes the sodium uptake data with bicarbonate or gluconate buffer and the effects of valinomycin and SITS. Sodium uptake with gluconate buffer was $1.4 \pm 0.3 \mathrm{nmol} / \mathrm{mg}$ protein per $5 \mathrm{~s}$ and increased to $2.5 \pm 0.4$ $\mathrm{nmol} / \mathrm{mg}$ protein per $5 \mathrm{~s}$ when bicarbonate was present $(P$ $<0.05)$. SITS $(0.5 \mathrm{mM})$ completely inhibited the stimulation of ${ }^{22} \mathrm{Na}$ uptake by bicarbonate. The addition of $7 \mu \mathrm{M}$ valinomycin,

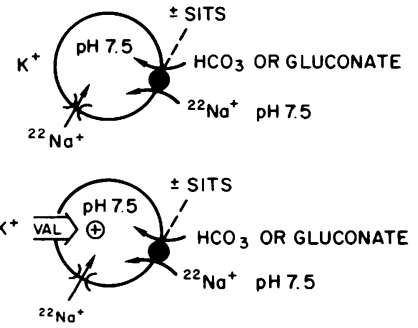

Figure 3. Experimental strategy for sodium/bicarbonate cotransport studies in basolateral membrane vesicles. 


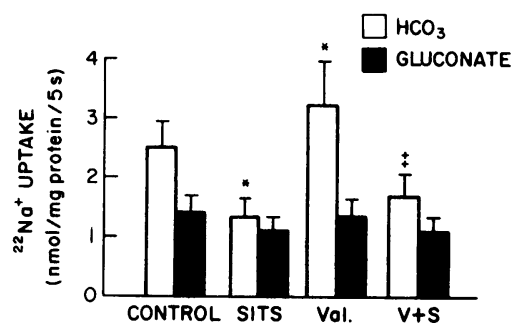

Figure 4. Effects of SITS and valinomycin on sodium/bicarbonate cotransport in bicarbonate and gluconate media.

${ }^{22} \mathrm{Na}$ uptakes of five different basolateral membrane vesicle preparations were measured by a rapid filtration technique at $5 \mathrm{~s}$ in eight different uptake conditions. Basolateral membrane vesicles were preincubated with a buffer con-

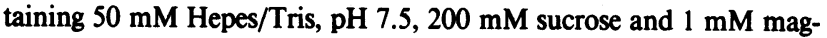
nesium gluconate. The uptake medium contained $50 \mathrm{mM}$ Hepes/ $\mathrm{KOH}, \mathrm{pH} 7.5,1 \mu \mathrm{Ci}{ }^{22} \mathrm{Na}, 10 \mathrm{mM}$ sodium gluconate, $25 \mathrm{mM}$ potassium bicarbonate or gluconate, $90 \mathrm{mM}$ potassium gluconate, and 1 $\mathrm{mM}$ magnesium gluconate. Final concentrations of bicarbonate and sodium were 21 . and $8.3 \mathrm{mM}$, respectively. Valinomycin $(7 \mu \mathrm{M})$ and $0.5 \mathrm{mM}$ SITS were present when indicated. Each bar denotes mean $\pm \mathrm{SE}$ of paired experiments $(n=5)$. Asterisk and double dagger denote statistically significant differences from controls based on paired comparisons (paired $t$ test; $P<0.05$ and $P<0.01$ respectively).

which established an inwardly directed potassium diffusion potential, increased ${ }^{22} \mathrm{Na}$ uptake from $2.5 \pm 0.4 \mathrm{nmol} / \mathrm{mg}$ protein per $5 \mathrm{~s}$ to $3.4 \pm 0.7 \mathrm{nmol} / \mathrm{mg}$ protein per $5 \mathrm{~s}$ when bicarbonate was present. This effect was also inhibited by SITS. On the other hand there was no effect of valinomycin or SITS on ${ }^{22} \mathrm{Na}$ uptake when gluconate rather than bicarbonate was present. The addition of valinomycin increased the difference between ${ }^{22} \mathrm{Na}$ uptake with bicarbonate-containing media and that with gluconate media from $1.1 \pm 0.2 \mathrm{nmol} / \mathrm{mg}$ protein per $5 \mathrm{~s}$ to $2.0 \pm 0.5 \mathrm{nmol} /$ $\mathrm{mg}$ protein per $5 \mathrm{~s}$. The mean-paired increase of $0.9 \pm 0.4 \mathrm{nmol} /$ $\mathrm{mg}$ protein per $5 \mathrm{~s}$ was statistically significant $(P<0.05)$. The equilibrium values for ${ }^{22} \mathrm{Na}$ uptake and ${ }^{3} \mathrm{H}$-1-glucose space at 120 min were not significantly different between that with and without bicarbonate, and that with and without valinomycin (data not shown).

We interpret these findings as follows: ${ }^{22} \mathrm{Na}$ uptake was stimulated by bicarbonate and inhibited by SITS, consistent with the presence of a SITS-sensitive sodium/bicarbonate cotransporter. An interior-positive diffusion potential stimulated sodium uptake in the presence of bicarbonate, and this effect was inhibited by SITS. These results suggested that the sodium/bicarbonate cotransporter was electrogenic and carried a net negative charge. Alternatively, these results could be interpreted as a sodium-independent bicarbonate conductive pathway that was inhibited by stilbenes. This interpretation is not consistent with the stimulation of sodium uptake when valinomycin was present, or depolarization of the basolateral membrane potential reported in rat and rabbit proximal tubules when the bath sodium concentration was decreased (6-8). Another possible explanation of our results is a $\mathrm{CO}_{2} / \mathrm{HCO}_{3}$-stimulated sodium permeability. Such a transport mechanism could explain the observed stimulation of ${ }^{22} \mathrm{Na}$ uptake by bicarbonate, but not the previously observed effect of sodium gradients on bicarbonate transport (8-10). In addition, SITS would not be expected to inhibit a sodium conductance.

In the remaining experiments, bicarbonate-dependent ${ }^{22} \mathrm{Na}$ uptake refers to the difference between the initial rate of ${ }^{22} \mathrm{Na}$ uptake with bicarbonate buffer and the rate with gluconate buffer, in the presence of an inwardly directed potassium gradient and $7 \mu \mathrm{M}$ valinomycin. Fig. 1 shows that both bicarbonate-dependent (left) and bicarbonate-independent (right $)^{22} \mathrm{Na}$ uptake were accurately measured for intervals up to $3 \mathrm{~s}$ under maximal gradient conditions.

The effect of sodium concentration on bicarbonate-dependent ${ }^{22} \mathrm{Na}$ uptake was examined at a fixed bicarbonate concentration of $21 \mathrm{mM}$. The bicarbonate-dependent ${ }^{22} \mathrm{Na}$ uptake increased with increasing sodium concentration from 4 to $42 \mathrm{mM}$ (Fig. 5). Kinetic analysis with Eadie-Hofstee plots (19) showed a $V_{\max }$ of $2.7 \pm 0.9 \mathrm{nmol} / \mathrm{mg}$ protein and a $K_{\mathrm{m}}$ of $10.4 \pm 2.3 \mathrm{mM}$ for sodium (mean $\pm \mathrm{SE}$ for five separate experiments).

The effect of bicarbonate concentration on bicarbonate-dependent ${ }^{22} \mathrm{Na}$ uptake was examined next at a constant sodium concentration of $8 \mathrm{mM}$ (Fig. 6). Increasing the bicarbonate concentration from 1 to $42 \mathrm{mM}$ produced a complex pattern of stimulation of bicarbonate-dependent ${ }^{22} \mathrm{Na}$ uptake. An initial increase was observed at low bicarbonate concentrations, and a sigmoidal stimulation of bicarbonate-dependent ${ }^{22} \mathrm{Na}$ uptake occurred above $4 \mathrm{mM}$ bicarbonate. This biphasic relationship suggests that more than one bicarbonate ion is associated with the transport process, consistent with the previously described electrogenicity of this transport system (Fig. 4). The kinetic characteristics of the interaction of bicarbonate with the sodium/ bicarbonate cotransport system were analyzed using the Hill equation (19) and are presented in Fig. 7. The Hill equation is:

$v=\left[\mathrm{HCO}_{3}\right]^{h} \times V_{\max } /\left(K^{\prime}+\left[\mathrm{HCO}_{3}\right]^{h}\right)$,

where $v$ is the rate of transport of sodium, $\left[\mathrm{HCO}_{3}\right]$ is the bicarbonate concentration, $V_{\max }$ is the maximum transport rate, $K^{\prime}$ is a constant comprising the interaction factor between binding sites and the intrinsic association constant, and $h$ is the Hill coefficient. The logarithmic form of the Hill equation,

$\log \left(v / V_{\max }-v\right)=h \times \log \left(\mathrm{HCO}_{3}\right)-\log \left(K^{\prime}\right)$,

yields a plot of $\log \left(v / V_{\max }-v\right)$ vs. $\log \left(\mathrm{HCO}_{3}\right)$ with a slope of $h$. $V_{\max }$ was obtained from an Eadie-Hofstee plot of the data with high bicarbonate concentrations presented in Fig. 6. The Hill plot of the data from Fig. 6 was linear between bicarbonate concentrations of 0.8 and $42 \mathrm{mM}$, with a Hill coefficient of $1.21 \pm 0.12$ (mean \pm SD, Fig. 7). The $95 \%$ confidence interval for the Hill slope was $1.21 \pm 0.29$ (d.f. $=6$ ). Similar analysis of the data from Fig. 5 gave a Hill coefficient of $1.05 \pm 0.10$ (mean \pm SD), with a $95 \%$ confidence interval of $1.05 \pm 0.32$ (d.f. $=3$ ).

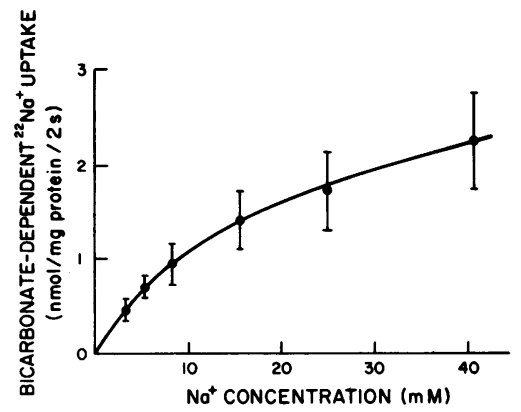

Figure 5. Effect of sodium concentration on bicarbonate dependent ${ }^{22} \mathrm{Na}$ uptake. The $y$ axis is the difference between the sodium uptake with bicarbonate-containing uptake medium ( 21 $\mathrm{mM}$ ) and that without bicarbonate (gluconate substituted). The $x$ axis is the final sodium concentration of the uptake medium. ${ }^{22} \mathrm{Na}$ uptakes were measured by a rapid filtration technique at $2 \mathrm{~s}$ in the presence of $7 \mu \mathrm{M}$ valinomycin. Each point represents mean \pm SE of five transport studies with different basolateral membrane preparations. Eadie-Hofstee plots showed $V_{\max }$ and $K_{\mathrm{m}}$ values of $2.7 \pm 0.9 \mathrm{nmol} / \mathrm{mg}$ protein per $2 \mathrm{~s}$ and $10.4 \pm 2.2 \mathrm{mM}$ sodium, respectively (mean $\pm \mathrm{SE}, n=5$ ). 


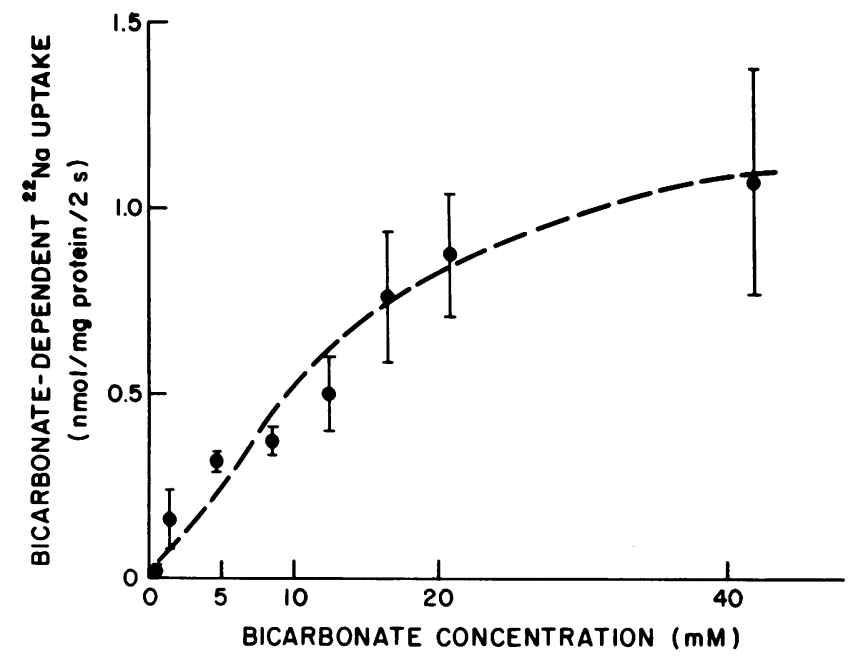

Figure 6. Effect of bicarbonate concentration on bicarbonate-dependent ${ }^{22} \mathrm{Na}$ uptake. Concentration of bicarbonate was changed as shown in the figure at a constant sodium concentration of $8 \mathrm{mM} .{ }^{22} \mathrm{Na}$ uptakes were measured by a rapid filtration technique at $2 \mathrm{~s}$ in the presence of $7 \mu \mathrm{M}$ valinomycin. Each point represents the mean $\pm \mathrm{SE}$ of seven uptake studies with different basolateral membrane preparations. The dotted line was drawn based upon the Hill coefficients from Fig. 7.

Finally, the effect of DIDS on the sodium/bicarbonate cotransport system in basolateral membrane was tested. All experiments were performed with an inwardly directed potassium gradient and in the presence of valinomycin. The extravesicular concentrations of sodium and bicarbonate were $5.8 \pm 42 \mathrm{mM}$ and $21 \mathrm{mM}$ respectively. DIDS was added to both the preincubation buffer and the uptake medium at a final concentration of $50 \mu \mathrm{M}$. DIDS dccreased the $V_{\max }$ of bicarbonate-dependent ${ }^{22} \mathrm{Na}$ uptake from a control value of $1.57 \mathrm{nmol} / \mathrm{mg}$ protein per $2 \mathrm{~s}$ to $0.88 \mathrm{nmol} / \mathrm{mg}$ protein per $2 \mathrm{~s}(44 \%$ inhibition, $P<.05$, paired $t$ test), but the $K_{\mathrm{m}}$ for sodium was not significantly altered (Table I).

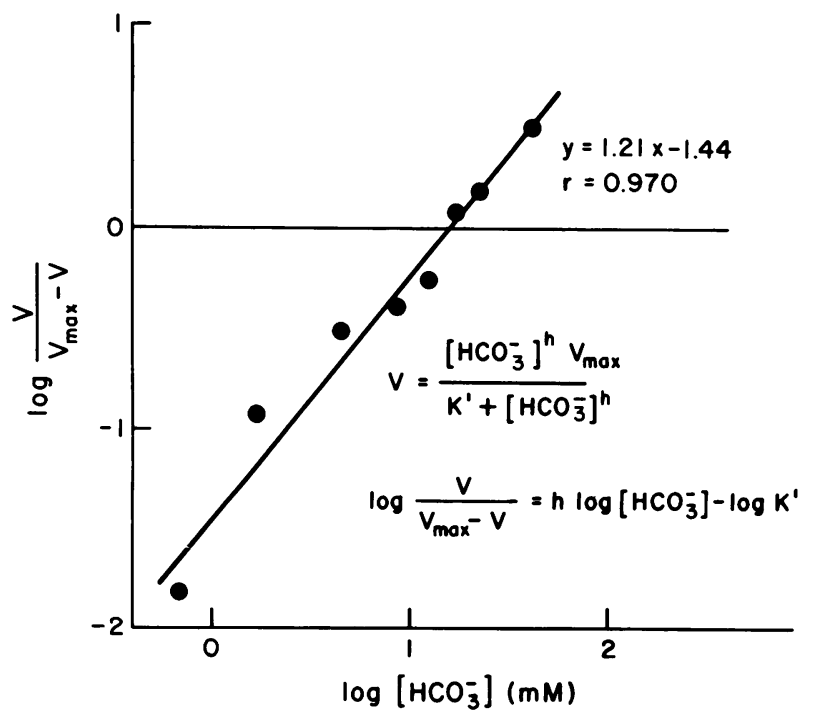

Figure 7. Kinetic analysis of bicarbonate-dependent ${ }^{22} \mathrm{Na}$ uptake (Hill plot).
Table I. Effect of DIDS on Bicarbonate-dependent ${ }^{22} \mathrm{Na}$ Uptake

\begin{tabular}{lll}
\hline & $V_{\operatorname{mex}}$ & $K_{\mathrm{m}}$ for sodium \\
\hline & $n$ mol/mg protein per $2 s$ & $m M$ \\
Control & $1.57 \pm 0.63$ & $10.1 \pm 3.0$ \\
DIDS $(50 \mu \mathrm{M})$ & $0.58 \pm 0.40^{*}$ & $8.2 \pm 3.7$ \\
\hline
\end{tabular}

Basolateral membrane vesicles were preincubated with $200 \mathrm{mM}$ sucrose, $50 \mathrm{mM}$ Hepes/Tris, pH 7.5, $1 \mathrm{mM}$ magnesium gluconate and 7 $\mu \mathrm{M}$ valinomycin. The final concentrations in the uptake media were 6-42 mM sodium gluconate, $21 \mathrm{mM}$ potassium gluconate or potassium bicarbonate, $95 \mathrm{mM}$ potassium gluconate, and $2 \mu \mathrm{Ci}^{22} \mathrm{Na}$. Isomolarity was maintained by addition of $n$-methyl glucamine-gluconate. DIDS $(50 \mu \mathrm{M})$ was present in the preincubation buffer and uptake media when indicated. Kinetic parameters (mean $\pm \mathrm{SE}$ ) were obtained from studies with four separate vesicle preparations.

* Significantly different from control $(P<0.05)$.

\section{Discussion}

Technical considerations. The rate of sodium/bicarbonate cotransport was determined by calculating the difference between ${ }^{22} \mathrm{Na}$ uptake with bicarbonate buffer and that with gluconate buffer, in the presence of an inwardly directed potassium gradient and $7 \mu \mathrm{M}$ valinomycin. ${ }^{22} \mathrm{Na}$ uptake with gluconate buffer might slightly overestimate a true zero value; the sodium/bicarbonate cotransporter might have some affinity for gluconate or hydroxyl and transport it to a limited extent. Because we did not find any effect of SITS, an anion transport inhibitor $(20,21)$ on ${ }^{22} \mathrm{Na}$ uptake in gluconate medium (Fig. 4), and the substitution of gluconate with cyclamate had no effect on ${ }^{22} \mathrm{Na}$ uptake, it seems likely that the difference between ${ }^{22} \mathrm{Na}$ uptake in the presence of bicarbonate and gluconate is an accurate measure of the rate of sodium/bicarbonate cotransport. The selectivity of this cotransporter for anions other than bicarbonate, gluconate, and cyclamate remains to be examined.

The driving forces for sodium/bicarbonate cotransport in our experiments were the inwardly directed $\mathrm{K}^{+}$diffusion potential, the sodium concentration gradient, and the bicarbonate concentration gradient. Rapid diffusion of dissolved $\mathrm{CO}_{2}$ into basolateral membrane vesicles in the presence of carbonic anhydrase (22) could rapidly increase the intravesicular bicarbonate concentration, thereby dissipating the bicarbonate concentration gradient. In addition, increased intravesicular concentration of sodium and collapse of the potassium gradient leading to a decreased diffusion potential would decrease the rate of ${ }^{22} \mathrm{Na}$ uptake. The time course study (Fig. 1), performed with maximal gradient conditions, showed a linear relation between ${ }^{22} \mathrm{Na}$ uptake and incubation time up to $3 \mathrm{~s}$, which then fell off at longer time points. This linearity was observed with bicarbonate-dependent ${ }^{22} \mathrm{Na}$ uptake (Fig. 1, left), as well as with the bicarbonateindependent component (right). Importantly, the linear regressions had a $Y$-intercept that was not different than zero, indicating that the driving forces were relatively constant when the initial measurements were made. Therefore, we used 2-s uptakes as a measure of initial rate for the kinetic analyses. The $\mathrm{pH}$ stability of the uptake media with different bicarbonate concentrations was confirmed by preliminary experiments (Fig. 2). Increased $\mathrm{pH}$ of the incubation buffer will establish a pH gradient between the intra- and extravesicular space, although the present studies were intended to have the same $\mathrm{pH}$ inside and out. This deviation 
in the incubation conditions was minimized by using relatively high concentrations of Tris/Hepes buffer and by preparing each individual uptake medium immediately before use.

Presence of electrogenic sodium/bicarbonate cotransport. In the first experiment, we have identified an electrogenic cotransporter for bicarbonate and sodium in basolateral membrane vesicles from the rabbit renal cortex with the following findings: ${ }^{22} \mathrm{Na}$ uptake was stimulated by bicarbonate and inhibited by SITS, consistent with sodium/bicarbonate cotransport. An interior-positive potassium diffusion potential stimulated ${ }^{22} \mathrm{Na}$ uptake in the presence of bicarbonate, and this effect was inhibited by SITS. This diffusion potential would decrease $\mathrm{Na}^{+}$entry by simple diffusion (Fig. 3). That interior-positive diffusion potential stimulated ${ }^{22} \mathrm{Na}$ uptake when bicarbonate was present (Fig. 4) suggests the presence of an electrogenic sodium/bicarbonate cotransporter. (In fact, since the preliminary studies presented in Fig. 4 were done with 5-s uptake measurements, the stimulatory effects of bicarbonate and potassium diffusion potential may have been underestimated.) Studies of the intact proximal tubule (6-10) support this suggestion, rather than the possible presence independent sodium and bicarbonate conductive pathways. Furthermore, studies by Grassl et al. (23) have demonstrated an "overshoot" in bicarbonate-dependent ${ }^{22} \mathrm{Na}$ uptake in basolateral membrane vesicles, consistent with a cotransport process. An overshoot was demonstrated in the previous study (23), using $1 \mathrm{mM}{ }^{22} \mathrm{Na}$ with an inwardly-directed bicarbonate gradient ( $55 \mathrm{mM})$ and $\mathrm{pH}$ gradient (1.5 $\mathrm{pH} \mathrm{U})$. We have not observed an overshoot in bicarbonate-dependent ${ }^{22} \mathrm{Na}$ uptake when the interior and exterior $\mathrm{pH}$ were both 7.5 , as in the present experiments.

The sodium/bicarbonate cotransport system was previously proposed from studies of perfused tiger salamander proximal tubules in vitro (5), rat proximal tubules in vivo (8-10), and perfused rabbit proximal straight tubules in vitro $(6,7)$. As described in the Methods section, the basolateral membrane vesicle preparation used in our studies is oriented right-side out, so the translocation of sodium and bicarbonate in the present experiments is in the reverse direction compared with the usual physiological condition. Therefore, we may consider this cotransport system to be reversible. Whether or not the kinetic features are identical in both directions is an important question that must be resolved before the kinetic features obtained with basolateral membrane vesicles can be applied to the in vivo setting. The SITS inhibition of sodium/bicarbonate cotransport is also consistent with the right-side-out orientation of the vesicles, because SITS inhibits anion transport only when applied to the outside of red blood cell membranes (20).

The presence of a chloride/bicarbonate exchanger has also been described in basolateral membrane vesicles from proximal tubular cells (24; Eveloff, J., and D. G. Warnock, unpublished observations). Burckhardt et al. $(25,26)$ have examined the effects of pH gradients on sodium sulfate cotransport in basolateral membrane vesicles, but not the effects of bicarbonate on this system. The present studies were done without chloride, so that chloride/bicarbonate exchange could not account for any of the present findings. Preliminary studies from Grassl et al. (23) confirm the finding of a sodium/bicarbonate cotransporter in basolateral vesicles from the rabbit renal cortex. The relative importance and relationship between these two distinct bicarbonate transport systems must be examined in further detail. However, studies of intact tubules have revealed that complete removal of sodium inhibits most of the basolateral membrane bicarbonate permeability, which suggests that the sodium/bicarbonate cotransporter is the major basolateral membrane bicarbonate transport mechanism $(8,10)$.

Effect of sodium concentration on bicarbonate-dependent ${ }^{22} \mathrm{Na}$ uptake. We found that increasing the external concentration of sodium accelerated bicarbonate-dependent sodium uptake, with an apparent $K_{\mathrm{m}}$ of $10.4 \mathrm{mM}$ for sodium when the external bicarbonate concentration was fixed at $21 \mathrm{mM}$ (Fig. 5). Recent studies in the rat proximal tubule cell have revealed that the intracellular sodium activity measured with sodium-selective microelectrodes (27) is $13 \mathrm{mM}$, and the intracellular sodium concentration determined by microprobe analysis is $19 \mathrm{mmol} /$ $\mathrm{kg}$ wet wt (28). If $K_{\mathrm{m}}$ for sodium is similar on both sides of the basolateral membrane, then our finding that $K_{\mathrm{m}}$ for sodium is $10.3 \mathrm{mM}$ suggests that the intracellular concentration of sodium may have an important role in regulating bicarbonate exit from the proximal tubular cell and thus in regulating intracellular $\mathrm{pH}$ $(9,10)$.

Effect of bicarbonate concentration on bicarbonate-dependent ${ }^{22} \mathrm{Na}$ uptake. The results presented in Fig. 6 show that variations in the bicarbonate concentration between 10 and $20 \mathrm{mM}$ are associated with parallel changes in the rate of bicarbonate-dependent ${ }^{22} \mathrm{Na}$ uptake. These findings suggest that physiologic concentrations of bicarbonate may regulate the rate of sodium/ bicarbonate cotransport across the basolateral membrane, if it can be assumed that the kinetic features of this exit pathway are similar to those described with the present uptake studies in right-side-out basolateral membrane vesicles.

Hill analysis of bicarbonate-dependent ${ }^{22} \mathrm{Na}$ uptake (Fig. 7) showed that one or more bicarbonate ions are involved in this transporter when translocation occurs. Since the Hill analysis requires that there be equivalent substrate binding sites with marked cooperativity, the Hill coefficient may underestimate the actual number of bicarbonate binding sites. Recent studies by Yoshitomi and Fromter (8) have suggested that the stoichiometric ratio is three net negative charges per sodium ion. Soleimani et al. (29) have also reported the bicarbonate/sodium stoichiometric ratio to be $3: 1$, by thermodynamic analysis of ${ }^{22} \mathrm{Na}$ uptake in rabbit cortical basolateral membrane vesicles. The present results are not necessarily inconsistent with these conclusions, even though the Hill slope of our data (Fig. 7) was not significantly different from unity, because the Hill slope only provides a minimal estimate of the number of bicarbonate ion binding sites.

Another possible explanation for the low Hill slope is a sodium carbonate/bicarbonate cotransport system. Studies by Boron and Russell (30) in the squid axon have been interpreted in terms of a sodium carbonate ion pair/chloride exchange model for transport. Becker and Duhm (31) have described a sodium carbonate/bicarbonate exchanger in red cell membranes. Analogously, the bicarbonate exit step of basolateral membranes could represent a sodium carbonate/bicarbonate cotransport system. A sodium carbonate/bicarbonate cotransport model would carry two net negative charges and have two anionic binding sites. In this configuration, there would be transport of three negative charges $\left(\mathrm{CO}_{3}^{-}+\mathrm{HCO}_{3}^{-}\right)$for every positive charge $\left(\mathrm{Na}^{+}\right)$, a ratio consistent with the charge stoichiometric ratio (3:1) observed by Yoshitomi et al. (8) and Soleimani et al. (29). Furthermore, the Hill slope of 1.21 (Fig. 7) could result from two distinct anionbinding sites. Further studies are required to define the existence and precise kinetic features of the sodium-coupled bicarbonate/ carbonate exit step of the basolateral membrane. At present, we 
can conclude that the stoichiometric ratio is necessarily greater than unity because the system is electrogenic (Fig. 4).

Effect of DIDS on bicarbonate-dependent ${ }^{22} \mathrm{Na}$ uptake. SITS and DIDS are well described inhibitors of anion transport in red blood cells (20). Ullrich et al. (21) and Chan et al. (32) reported that application of SITS to the pericapillary side inhibited bicarbonate reabsorption in the rat proximal tubule. Cohen et al. (33) reported that $0.5 \mathrm{mM}$ SITS, when added to the serosal side of turtle urinary bladders, inhibited proton secretion by $>80 \%$ and increased cell $\mathrm{pH}$, consistent with inhibition of a bicarbonate exit step. Kleinman et al. (34) also described a bicarbonate-dependent, SITS-sensitive cell acidification step in suspensions of rabbit renal tubule fragments. All of these studies are consistent with inhibition of a bicarbonate exit step by disulfonic stilbenes.

Although Koschier et al. (35) reported that DIDS competitively inhibited PAH uptake in rabbit renal cortical slices, our experiments suggest that DIDS is predominantly a noncompetitive inhibitor of bicarbonate-dependent ${ }^{22} \mathrm{Na}$ uptake (Table I). While it might be expected that DIDS would competitively inhibit the interaction between bicarbonate and anion-binding sites, the present studies examined a range of sodium concentrations at a single bicarbonate concentration. It is known that DIDS covalently binds to the band 3 protein (19). This sort of interaction may account for the decrease in $V_{\max }$ of bicarbonatedependent sodium uptake observed when basolateral membrane vesicles were pretreated with DIDS. If the isothiocyanate groups of DIDS form covalent bonds with the sodium/bicarbonate cotransporter, then this probe may be a useful tool for further characterization and identification of this transport system in the basolateral membrane.

In summary, an exit mechanism for bicarbonate from the mammalian kidney proximal tubule cell was examined in basolateral membrane vesicles prepared from the rabbit renal cortex. Sodium/bicarbonate cotransport was demonstrated, and this process was found to be electrogenic. This finding is consistent with a bicarbonate/sodium stoichiometric ratio greater than unity. The sodium/bicarbonate/carbonate cotransport system may be regulated by the intracellular concentrations of sodium in the proximal tubular cell. It provides a mechanism by which both sodium and bicarbonate/carbonate can be transported across the basolateral membrane of the proximal tubule cell.

\section{Acknowledgments}

We would like to thank Floyd C. Rector, Jr., for his ongoing support and helpful criticism of this work.

This project was supported by the Veterans Administration Research Service, and National Institutes of Health grants AM-19407 (Dr. Warnock), AM-01229 (Dr. Alpern), and AM-30722 (Dr. Eveloff). Dr. Akiba was a post-doctoral fellow in the Cardiovascular Research Institute during these studies, and was supported in part by a stipend from the Northern California Affiliate of the National Kidney Foundation.

\section{References}

1. Alpern, R. J., D. G. Warnock, and F. C. Rector, Jr. 1986. Renal acidification mechanisms. In The Kidney. 3rd ed. B. M. Brenner and F. C. Rector, Jr., editors. W. B. Saunders \& Co., Philadelphia, 1:206249.

2. Yoshitomi, K., and E. Fromter. 1984. Cell pH of rat renal proximal tubule in vivo and the conductive nature of peritubular $\mathrm{HCO}_{3-/ \mathrm{OH}^{-}}$exit. Pfluegers Arch. Eur. J. Physiol. 402:300-305.

3. Burckhardt, B.-Ch., K. Sato, and E. Fromter. 1984. Electrophys- iological analysis of bicarbonate permeation across the peritubular cell membrane of rat kidney proximal tubule. I. Basic observations. Pfluegers Arch. Eur. J. Physiol. 401:34-42.

4. Matsushima, Y., B. Cohen, W. B. Guggino, and G. Giebisch. 1984. Electrical effects of potassium and bicarbonate on proximal tubule cells of Necturus. J. Membr. Biol. 79:145-152.

5. Boron, W. F., and E. L. Boulpaep. 1983. Intracellular pH regulation in the renal proximal tubule of the salamander: basolateral $\mathrm{HCO}_{3}^{-}$transport. J. Gen. Physiol. 81:53-94.

6. Biagi, B. A. 1985. Effect of the anion transport inhibitor, SITS, on the proximal straight tubule of the rabbit perfused in vitro. J. Membr. Biol. 88:25-31.

7. Sasaki, S., T. Shiigai, and J. Takeuchi. 1985. Intracellular pH in the isolated perfused rabbit proximal straight tubule. Am. J. Physiol. 249:F417-F423.

8. Yoshitomi, K., B.-Ch. Burckhardt, and E. Fromter. 1985. Rheogenic sodium-bicarbonate cotransport in the peritubular cell membrane of rat renal proximal tubule. Pfluegers Arch. Eur. J. Physiol. 405:360366.

9. Alpern, R. J., and M. Chambers. 1986. Cell pH in the rat proximal convoluted tubule: regulation by luminal and peritubular $\mathrm{pH}$ and sodium concentration. J. Clin. Invest. 78:502-510.

10. Alpern, R. J. 1985. Mechanism of basolateral membrane $\mathrm{H}^{+} /$ $\mathrm{OH}^{-} / \mathrm{HCO}_{3}$-transport in the rat proximal convoluted tubule: a sodiumcoupled electrogenic process. J. Gen. Physiol. 86:613-636.

11. Jentsch, T. J., B. S. Schill, P. Schwartz, H. Matthes, S. K. Keller, and M. Wiederholt. 1985. Kidney epithelial cells of monkey origin (BSC1) express a sodium bicarbonate cotransport: characterization by ${ }^{22} \mathrm{Na}^{+}$ measurements. J. Biol. Chem. 260:15554-15560.

12. Ives, H. E., V. J. Yee, and D. G. Warnock. 1983. Asymmetric distribution of the $\mathrm{Na}^{+} / \mathrm{H}^{+}$antiporter in the renal proximal tubule epithelial cell. J. Biol. Chem. 258:13513-13516.

13. Turner, R. J., and A. Moran. 1982. Heterogeneity of sodiumdependent D-glucose transport sites along the proximal tubule: evidence from vesicle studies. Am. J. Physiol. 242:F406-F414.

14. Schoner, W., C. von Ilberg, R. Krammer, and W. Seubert. 1967. On the mechanism of $\mathrm{Na}^{+}$- and $\mathrm{K}^{+}$-stimulated hydrolysis of adenosine triphosphate. Eur. J. Biochem. 1:334-343.

15. Seiler, S., and S. Fleischer. 1982. Isolation of plasma membrane vesicles from rabbit skeletal muscle and their use in ion transfer studies. J. Biol. Chem. 257:13862-13871.

16. Scoble, J. E., S. Mills, and K. A. Hruska. 1985. Calcium transport in canine renal basolateral membrane vesicles: effect of parathyroid hormone. J. Clin. Invest. 75:1096-1105.

17. Lowry, O. H., N. J. Rosenbrough, A. L. Fine, and R. J. Randall. 1951. Protein measurement with the Folin phenol reagent. J. Biol. Chem. 193:265-273.

18. Wright, S. H., I. Kippen, and E. M. Wright. 1982. Stoichiometry of $\mathrm{Na}^{+}$-succinate cotransport in renal brush-border membranes. J. Biol. Chem. 257:1773-1778.

19. Segel, I. H. 1975. Enzyme Kinetics. John Wiley \& Sons, Inc., New York. 360-375.

20. Cabantchik, Z. I., P. A. Knauf, and A. Rothstein. 1978. The anion transport system of the red blood cell: the role of membrane protein evaluated by the use of probes. Biochim. Biophys. Acta. 519:239-302.

21. Ullrich, K. J., G. Capasso, G. Rumrich, F. Papavassiliou, and S. Kloss. 1977. Coupling between proximal tubule transport processes: studies with ouabain, SITS, and $\mathrm{HCO}_{3}$-free solutions. Pfluegers Arch. Eur. J. Physiol. 368:245-252.

22. Wistrand, P. J., and R. Kinne. 1977. Carbonic anhydrase activity of isolated brush border and basolateral membranes of renal tubule cells. Pfluegers Arch. Eur. J. Physiol. 370:121-126.

23. Grassl, S. M., and P. S. Aronson. 1986. Na- $\mathrm{HCO}_{3}$ cotransport in rabbit renal cortical basolateral membrane vesicles. Kidney Int. 29: 367. (Abstr.)

24. Grassl, S. M., L. P. Karniski, and P. S. Aronson. 1985. Cl- $\mathrm{HCO}_{3}$ exchange in rabbit renal cortical basolateral membrane vesicles. Kidney Int. 27:282. (Abstr.) 
25. Burckhardt, G. 1984. Sodium-dependent dicarboxylate transport in rat renal basolateral membrane vesicles. Pfluegers Arch. Eur. J. Physiol. 401:254-261.

26. Low, I., T. Friedrich, and G. Burckhardt. 1984. Properties of anion exchanger in rat renal basolateral membrane vesicles. Am. J. Physiol. 246:F334-F342.

27. Yoshitomi, K., and E. Fromter. 1985. How big is the electrochemical potential difference of $\mathrm{Na}^{+}$across rat renal proximal tubular cell membranes in vivo? Pfluegers Arch. Eur. J. Physiol. 405(Suppl. 1): S121-S126.

28. Gyory, A. Z., F. Beck, R. Rick, and K. Thurau. 1985. Electron microprobe analysis of proximal tubule cellular $\mathrm{Na}, \mathrm{Cl}$, and $\mathrm{K}$ element concentrations during acute mannitol-saline volume expansion in rats: evidence for inhibition of Na pump. Pfluegers Arch. Eur. J. Physiol. 403: 205-209.

29. Soleimani, S. M., S. M. Grassl, and P. S. Aronson. 1986. Stoichiometry of the $\mathrm{Na}-\mathrm{HCO}_{3}$ cotransport system in renal basolateral membrane vesicles. Clin. Res. 34:609. (Abstr.)
30. Boron, W. F., and J. M. Russell. 1983. Stoichiometry and ion dependencies of the intracellular pH-regulating mechanism in squid axons. J. Gen. Physiol. 81:373-399.

31. Becker, B. F., and J. Duhm. 1978. Evidence for anionic cation transport across the human erythrocyte membrane induced by divalent anions. J. Physiol. (Lond.). 282:149-168.

32. Chan, Y. L., B. Biagi, and G. Giebisch. 1982. Control mechanisms of bicarbonate transport across the rat proximal convoluted tubule. Am. J. Physiol. 242:F532-F543.

33. Cohen, L. H., A. Mueller, and P. R. Steinmetz. 1978. Inhibition of the bicarbonate exit step in urinary acidification by a disulfonic stilbene. J. Clin. Invest. 61:981-986.

34. Kleinman, J. G., R. A. Ware, and J. H. Schwartz. 1981. Anion transport regulates intracellular $\mathrm{pH}$ in renal cortical tissue. Biochim. Biophys. Acta. 648:87-92.

35. Koschier, F. J., M. F. Stokols, J. M. Goldinger, M. Acara, and S. K. Hong. 1980. Effect of DIDS on renal tubular transport. Am. J. Physiol. 238:F99-F106. 